\title{
mHealth - an Ultimate Plafform to Serve the Unserved
}

\author{
S. Akter, P. Ray \\ Asia-Pacific ubiquitous Healthcare research Centre (APuHC), Information Systems, Technology and \\ Management, Australian School of Business (ASB), University of New South Wales, Sydney, Australia
}

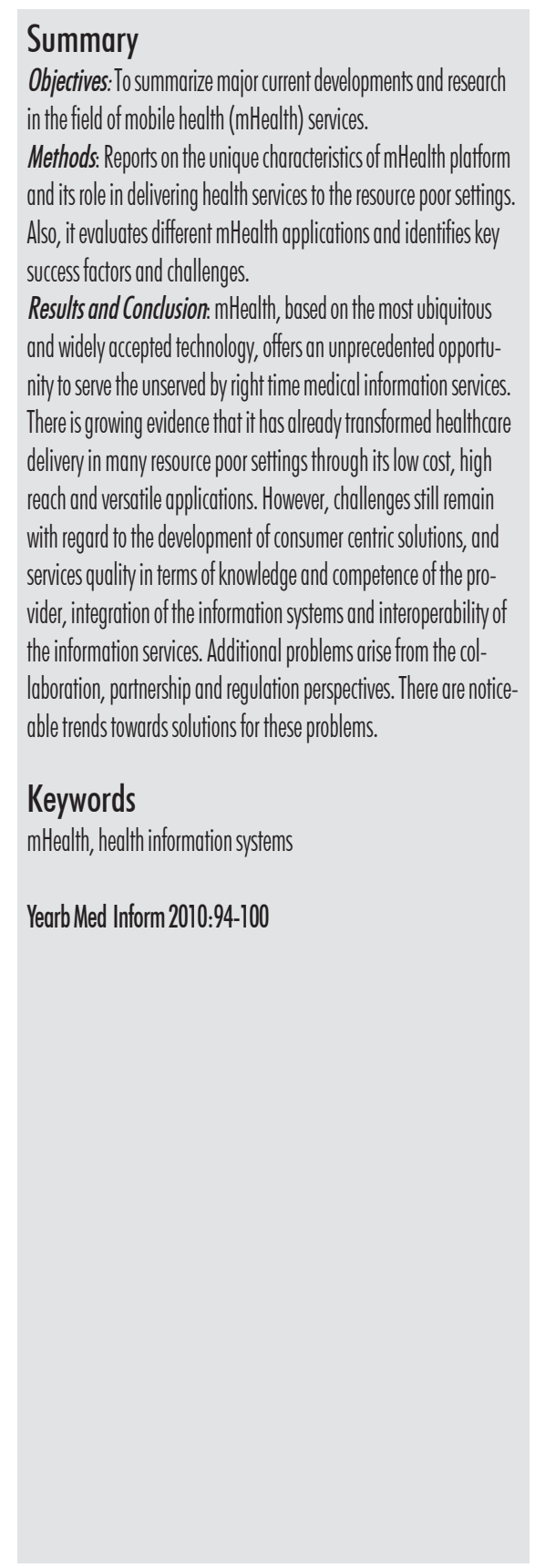

\section{Introduction}

Health challenges present arguably the most significant barrier to sustainable global development. The introduction of information and communication technologies (ICT) in healthcare, especially the application of mobile communications, is transforming healthcare delivery by making it more accessible, affordable and available [1]. It has dramatically improved the decision making and production processes of health and healthcare by ensuring the right information to the right person and at the right time [2]. Furthermore, it has significantly facilitated information access, enhanced workflow, and promoted the evidencebased practice to make informed and effective decisions directly at the point of care [3-9]. Mobile Communications based healthcare (or, mHealth) has already been deployed for remote data collection, remote monitoring, and improved living standards of patients [11]. Mounting interests and growing body of evidence demonstrate the potential of mobile communications to radically improve healthcare in the most remote and resource-poor environments of the world [11]. The impact of mobile communications based healthcare (or, mHealth) is likely to be more farreaching than other developments, which create an urgent need to review the way this ubiquitous healthcare is meeting the needs and promising the change in global health care initiatives. Thus, the aim of this study is to synthesize the developments of mHealth around the world and discuss its potential to move forward.

\section{Definition of mHealth}

mHealth is defined as using mobile communications-such as PDAs and mobile phones-for health services and information [11]. In broad, it is defined as the use of portable devices with the capability to create, store, retrieve, and transmit data in real time between end users for the purpose of improving patient safety and quality of care [11]. Istepanian et al. [13] defined mHealth as the application of mobile communications and network technologies for healthcare [13]. Furthermore, IIuyemi [11] extended this definition by focusing on any wireless technologies (e.g., Bluetooth, GSM, GPRS/3G, wiFi, WiMAX) to transmit various health related data contents and services through mobile devices such as mobile phones, smart phones, PDAs, laptops and Tablet PCs. However, this definition has targeted only health workers as the sole users of mobile health services, but there many mHealth services which are being used by both patients and health workers, such as, mobile telemedicine services in India, Bangladesh and Mexico [14]. Focusing on such mHealth platform, Akter et al. [1] defined it as a personalized and interactive service whose main goal is to provide ubiquitous and universal access to medical advice and information to any users at any time over mobile platform. 
Tablel Definition of mHealth

\begin{tabular}{|l|l|}
\hline Study & Definition \\
\hline Istepanian et al. [13] & $\begin{array}{l}\text { mHealth refers to the emerging mobile communications and } \\
\text { network technologies for healthcare. }\end{array}$ \\
Mechael [12] & $\begin{array}{l}\text { It is a subset of eHealth using mobile devices to deliver health } \\
\text { services to the patients. } \\
\text { It refers to the application of embedded wireless devices to track } \\
\text { health related parameters. } \\
\text { It is a personalized and interactive service which provides } \\
\text { ubiquitous and universal access to medical advice and } \\
\text { information to any users at any time over mobile platform. [15] } \\
\text { It is defined as using mobile communications-such as PDAs } \\
\text { and mobile phones - for health services and information. }\end{array}$ \\
UN foundation \& Vodafone foundation [11] &
\end{tabular}

The extant literature defines mHelath as a subset of eHealth using mobile devices to deliver health services to the patients [12]. It is also seen as an essential component of pervasive health-care which is defined as right time health services to anyone by removing locational, time and other restraints while increasing both the coverage and quality of healthcare [16, 17].

In contrast, some researchers [18] have shifted from the existing view by identifying mHealth as a separate development. They suggest that mobile platform is the newest mass media based on some unique attributes which can be leveraged to empower patients and Healthcare service delivery. They report that mHealth alone has all the potentials to automate and speed up the healthcare delivery processes, reduce costs, facilitate service delivery, relate more closely to their patients and offer them more convenience and appeal to this new service. Furthermore, they believe it as a paradigm shift to improve ubiquitous healthcare around the world.

Overall this study believes that mHealth and eHealth are closely linked, their technologies work in conjunction, and both can improve global health outcomes in a coordinated manner [11].

\section{Why Health Services through Mobile Platform?}

Technology has the potential to solve many problems faced by the developed and developing countries which range from basic education to primary health care. The unique characteristics (e.g. easy accessibility, personalized solution and location based services) of mobile devices (e.g., mobile phone) compared with other platforms (see Table: 2) have made them attractive to the health sector. Besides, mobile platform is relatively inexpensive, faster and simpler than fixed phone platform to set-up in resource poor environments [19, 20]. Furthermore, mobile phones are also much easy to use than the Internet for those who are unfamiliar with complex technology [19]. At the moment, with
Table 2 Evaluation of Communication Channel [31] massive penetration of mobile phone networks globally and availability of low cost smart phones, the majority of the global population (more than 4 billion) who never had access to fixed line telephone or computer now use mobile phones for the right time communication and information [14]. This ubiquity is a central element in the promise of the mobile platform for health [11]. There is widespread evidence that this ubiquitous platform can scale well to combat evolving health challenges by ensuring lower cost, wider coverage and multiplying mHealth solutions [35].

Thus, inspired by the tremendous growth and impact of mHealth, global health policy-makers and providers are strengthening this platform as a new weapon to fight against global health crisis [11]. It is well accepted that this platform has the capacity to significantly expand access to communications and to provide right time healthcare solutions in the form of voice, video and data. Undoubtedly, it will empower providers with improved diagnoses and patients with right time services [11]. Thus, it is believed to transform health care by making resources available to health care professionals and patients with an efficient and robust infrastructure [13].

\section{Necessity of mHealth Services around the World}

Health services are often inadequate in the developing world because they are neither accessible nor affordable, and

\begin{tabular}{|l|c|c|c|c|c|}
\hline Features of channel & TV & Radio & Press & PC & Mobile \\
\hline Interactivity & None & None & None & High & High \\
Timeliness & None & Low & Avg & None & High \\
personalization & Low & None & Low & High & High \\
Context sensitivity & Low & Low & None & Low & High \\
\hline
\end{tabular}


when they are accessible, they are often dysfunctional, low in quality, and unresponsive to the needs of clients [1]. UN report [11] on MDGs (Millennium Development Goals) represents a formidable picture showing that an estimated 2.5 million newly infected HIV users in 2007. Furthermore, HIV and communicable diseases (Tuberculosis, Malaria etc.) continue to claim lives due to lack of knowledge or access to medication. According to WHO [12] '57 countries have critical shortages in health care workers, with a total deficit of 2.4 million health professionals worldwide.' Table 3 outlines the dire situation of primary health care in developing countries (e.g., India \& Bangladesh) in comparison with developed countries (e.g., USA \& UK) [14].

Within this context, mHealth has emerged as a viable solution to serve the pressing healthcare needs through its high reach and low cost solution. It is seen as an enabler of change in health care sector by ensuring the right information to the right person and at the right time [2]. The UN predicts that cell-phone ownership will reach 5 billion in 2010, with most growth in the developing world [41]. At present, "more than 50\% percent of mobile users are in developing countries, and it is estimated that by 2012 , more than $50 \%$ of individuals in remote areas of the world will have a mobile phone" [41]. This dramatic penetration of mobile phones in the low and middle income countries is playing a critical role in reducing the digital divide in healthcare. It is expected that mHelath will soon transform the face and context of healthcare service delivery around the world by improving the overall patient care and the provision of personalized health services [42].

Table 4 shows that, for every 5300 people in the developing world, there are only 11 hospital beds. Five percent of the population has access to computers whereas $43 \%$ of the population own mobile phones. Indeed, mobile phones, as an ICT platform, have far greater penetration than other platform, and are potentially capable to meet the unserved health needs of patients [11].

Table 3 Primary Health Care Indicators: A comparative assessment between Developed and Developing countries [14]

\begin{tabular}{|l|l|l|l|l|l|l|}
\hline Countries & $\begin{array}{l}\text { Infant Mor- } \\
\text { tality rate } \\
\text { (per 1000) in } \\
2006\end{array}$ & $\begin{array}{l}\text { Maternal } \\
\text { Mortality } \\
\text { (per100000) } \\
\text { in 2005 }\end{array}$ & $\begin{array}{l}\text { Years of life } \\
\text { lost due to } \\
\text { communicable } \\
\text { disease (\%) } \\
\text { in } 2002\end{array}$ & $\begin{array}{l}\text { Births at- } \\
\text { tended by } \\
\text { skilled } \\
\text { health per- } \\
\text { sonnel (\%) }\end{array}$ & $\begin{array}{l}\text { Hospital beds } \\
\text { (per 10000) }\end{array}$ & $\begin{array}{l}\text { Total } \\
\text { Health } \\
\text { workers } \\
\text { (per } \\
10000)\end{array}$ \\
\hline India & 57 & 450 & 58 & $47(2006)$ & $9(2003)$ & $14(2003)$ \\
Bangladesh & 52 & 570 & 60 & $20(2006)$ & $3(2001)$ & $5(2001)$ \\
UK & 5 & 8 & 10 & $99(1998)$ & $39(2004)$ & $15(2001)$ \\
USA & 7 & 11 & 9 & $100(2004)$ & $32(2005)$ & $125(1999)$ \\
\hline
\end{tabular}

Table 4 Technology and health related statistics for developing countries [11]

\begin{tabular}{|c|l|l|l|}
\hline \multirow{2}{*}{\begin{tabular}{c|l|l|} 
For every 5,300 \\
people in developing
\end{tabular}} & $\begin{array}{l}\text { Hospital } \\
\text { Beds }\end{array}$ & $\begin{array}{l}\text { Mobile } \\
\text { phones }\end{array}$ & Computers \\
\cline { 2 - 4 } countries & 11 & $\begin{array}{l}2293 \text { or } \\
43 \%\end{array}$ & 305 or $5 \%$ \\
\hline
\end{tabular}

Table 5 mHealth Applications around the World

\begin{tabular}{|c|c|c|}
\hline Applications & Service & Some Popular Projects and Countries \\
\hline Remote Data Collection & $\begin{array}{l}\text { Health survey using } \\
\text { e-forms }\end{array}$ & $\begin{array}{l}\text { Episurveyor in Kenya, Uganda and Zambia ( }+20 \\
\text { countries of sub Saharan Africa) (see case 1) }\end{array}$ \\
\hline $\begin{array}{l}\text { Disease \& epidemic outbreak } \\
\text { tracking }\end{array}$ & SMS & Application of Frontline SMS Worldwide (see Case 2) \\
\hline $\begin{array}{l}\text { Diagnostic \& Treatment } \\
\text { Support }\end{array}$ & Voice & $\begin{array}{l}\text { Mobile telemedicine platforms such as, HMRI in India, } \\
\text { Healthline in Bangladesh, Medicall Home in Mexico, RICE } \\
\text { in Vietnam (see case 3) }\end{array}$ \\
\hline Remote Monitoring & SMS\& Voice & $\begin{array}{l}\text { Cell life project for HIV in South Africa, Reminder for TB } \\
\text { treatment in Thailand and Philippines }\end{array}$ \\
\hline Education and awareness & SMS\& Voice & $\begin{array}{l}\text { Project Masiluleke in South Africa and Text to change in } \\
\text { Uganda }\end{array}$ \\
\hline Communication \& Training & Voice & Training nurses in the Caribbean \& Guatemala \\
\hline
\end{tabular}

\section{5 mHealth and its Applica- tions around the World}

A growing number of countries around the world (see Table 5) are using mobile communications to address various healthcare needs which include education \& awareness, remote data collection, remote monitoring, communication \& training, disease \& outbreak tracking, diagnostic and treatment support [1]. New helpful functionalities are arising with mobile devices and embedded systems, such as, smart homes and ambient assisted living [24]. A recent study shows that there are fifty-one mHealth programs that are being operated in 26 developing countries [11].

Different types of mHealth services are in place. In some settings, it is used as the ultimate platform for diagnostic and treatment support, whereas in other places, it is used as remote information tools that provide information to the stakeholders. Overall, mHealth applications include text, voice, video and data based solutions. 
Case 1: Data collection and Disease outbreak surveillance [21, 11]

Mobile data collection continues to be the largest concentration of mobile applications for services. In this case, EpiSurveyor of DataDyne.org pioneered an open-source application that allows the community health workers (CHWs) to exchange information using smart phones. CHWs can download electronic patient information sheet from online, fill that with mobile phone and send to the computer at a central clinic for analysis in real time. The ease of use and usefulness of EpiSurveyor enable clinical teams to have accurate health statistics. In tracking the outbreak of diseases, this application plays an instrumental role in analyzing bulk data immediately. For example, in Zambia the program has been used to track the immunization program and elsewhere to monitor stocks of essential drugs in a region's health clinics. CHWs prefer this program because they can do all their tasks using their own mobile phones. In sub-Saharan Africa, CHWs at regional office of each country is using this application, which is supported by the mHealth alliance, established by the UN foundation-Vodafone foundation technology partnership. This transition towards electronic data exemplifies an example of a leapfrog technology to develop a reliable and robust electronic health records.Since EpiSurveyor is built on open source software, so it allows the project to be cost effective, collaborative, andsuitable for quick revision and adaptation. However, its operation depends on using sophisticated smart phones (e.g., blackberry) and stable Internet connection, which are still rare in the developing world. Thus, web independent mHealth solutions based on low cost smart phones would be more scalable and sustainable.

The pervasiveness of the mobile platform is being harnessed to spread health information, especially about sexual health and HIV prevention [21]. In Uganda, a local mobile phone company in collaboration with AIC (Aids information centre) provides bulk SMS messages to clients to give them proper education on AIDS [14]. This program is known as 'Text-to-change' and aims to raise awareness on AIDS through voluntary counseling and HIV testing. Similarly, Project Masiluleke is functioning to fight the HIV and tuberculosis epidemics in South Africa. It al- lows users to send free "Please Call Me," or PCM, messages from their mobile phones to receive necessary healthcare information [11, 21]. They receive immediate feedback for consultation from the local HIV and tuberculosis call centers. Projects for remote health information dissemination like Project Masiluleke in South Africa and Text to-Change in Uganda have been hugely successful. Similar services are also available in Nigeria in the 'Learning about living' project, in which people are made aware of AIDS through text messaging. In Georgia, a similar awareness program is run through video contents. In India, information on HIV/ AIDS is provided in an engaging and fun way through mobile game services [9]. The games are tailored to target users from different social and demographic groups and run on more than 100 types of mobile phones ranging from basic models to sophisticated smart phones [23].

Case 2: SMS based mHealth for pandemic surveillance [23]

FrontlineSMS is a free open-source software package created for Non Government Organizations in the developing world. Using only a PC and a cell phone, FrontlineSMS creates an SMS- based communication hub that can be used anywhere with cellular network coverage without requiring an Internet connection. It has been used in that area in several different locations, notably at St. Gabriel's, a rural hospital in western Malawi. The hospital serves a population of 250,000 with only two physicians which allows the hospital to respond to requests for emergency medical care, track patients, record HIV and TB drug adherence, stay updated on patient status, mobilize remote communities for outreach testing, provide instant drug dosage/usage information, and connect HIV/AIDS support group members. The whole project was extremely inexpensive; the mobile phones were recycled, the laptop was donated and the ongoing cost (of SMS messages) is less than US\$10 per week. Therefore, FrontlineSMS presents a strong model for mHealth solution based on open source software. The sustainability of this project lies in its flexibility, low cost applications and web independent solutions in resource poor settings.
Case 3: Mobile telemedicine for treatment support [14]

".........Afiya lives in the rural Sylhet region of Bangladesh. For two days, her youngest daughter Rubina has been complaining of fatigue and has felt warm to the touch. Taking the child to the nearest clinic would cost Afiya a day's lost wages, round-trip bus fare, and clinic fees of Taka 200 (US\$ 3). Instead, Afiya and her husband use the family's mobile phone to dial '7-8-9,' the Healthline hotline service set up by TRCL, Ltd., a telemedicine firm, and GrameenPhone, the country's largest mobile network operator. The family quickly reaches a registered physician at Healthline's call center and receives the desired medical information. For the three minute call, Afiya pays only Taka 15 (US\$ 0.21) from her family's GrameenPhone pre-paid talk-time balance."

In Bangladesh, this mhealth platform receives 6000 to 10,000 calls per day. A survey of users reports that by using the service, most callers save travel time (98\%) and money (91\%), and experience shorter wait times $(97 \%)$ and reduced doctor's fees (83\%). Fiftyfive percent of calls to Healthline are from rural areas and $77 \%$ of callers are women. Of rural callers, $81 \%$ are women of whom twothirds are calling about their children's health. Most callers had income below the poverty line $(56 \%)$, and that most were located in rural areas $(63 \%)$. Of those in rural areas, $72 \%$ reported not having access to a modern healthcare provider within a 5-mile radius of their home.

In addition to text \& video, voice based mHealth services (mostly call centres) are becoming very popular in developing countries, such as, India, Mexico, Pakistan, South Africa and Bangladesh [14]. Under this platform, a user can easily access this service both in a non-emergency (headache, cold, cough, etc.) and an emergency situation (accident, burn, severe stomach pain, etc.) by simply dialing some unique digits (e.g. 789 in Bangladesh) from mobile phone. Users can instantly receive medical information, consultation, treatment, triage, diagnosis, referral and counseling from health professionals (registered physicians, nurses and paramedics) at an affordable price [1, 14].

mHealth solutions are also playing a critical role in disaster relief commu- 
nications. They help the health professionals and emergency relief workers to respond more quickly and effectively and support victims with necessary food and medicine [27]. Using mHealth solutions, the World Food Program (WFP) provided necessary food to 100 million disaster stricken people in 80 countries [27]. In this case, UN foundation and Vodafone foundation are providing vital telecommunication support to the UN and other humanitarian agencies during emergencies.

Overall, assessment of the mHealth projects around the world demonstrates that this platform improves healthcare delivery and makes healthcare truly effective [11]. There is strong evidence that it is serving millions in low income countries through right time treatment support [1, 14]. Furthermore, it has dramatically improved drug adherence rates up to $90 \%$ among HIV positive patients and TB patients through SMS reminders [11]. Other pertinent studies conducted in USA, Spain, Australia, Finland and Korea have shown the similar benefits of using mobile communications in diabetes self care, vaccination follow up and asthma [11]. Thus, mHealth programs around the world reflect an increasingly strong scenario of improved health outcomes.

\section{Key Success Factors for mHealth}

Based on the synthesis of mHealth literatures and analysis of existing service platforms, we have identified the following factors which play a crucial role to ensure the scalability and sustainability of mHealth programs around the world.

\subsection{Consumer Centric Solutions:}

Consumer centered (not health care institution centered) healthcare is now becoming a focal issue, because sustainability of the platform and em- powerment of the consumers are closely linked [39, 40]. According to Haux [39], "Research, still in an early stage, is focusing on consumer health features and services". Therefore, focusing on consumer needs, we have identified the following dimensions which play a critical role to ensure its organic growth.

\section{A. Affordability}

The greatest hurdle that we identified for mHealth projects is to ensure that services are affordable. It requires enough attention on how to reduce the cost of delivering healthcare services to a large number of people by using wireless infrastructure [16, 17]. Because, the ultimate scalability of the project depends on its ability to provide cost effective services [11]. Evidence from India and Bangladesh suggests that the cost of mobile telemedicine is too high for the majority of rural users [14]. In Bangladesh, mobile telemedicine platforms charges 15 taka (US\$ 0.22) for the first three minutes and 5 taka (US\$ $0.07)$ per minute thereafter, including value added tax (VAT). In comparison with the per capita income, this pricing is too expensive for the majority of rural users.

\section{B. Availability}

The wireless network coverage affects the data processing atmosphere and, ultimately, the scalability of mHelath solutions [16, 17]. Poor network coverage is still a major problem for implementing mHealth programs in developing countries. For instance, HMRI in India introduced medical call centers in a particular state; however, $50 \%$ of their daily calls are interrupted due to poor mobile network coverage [14].

\section{Awareness}

The majority of mobile phone users are not aware of mHealth services [14]. So it is necessary to aware these users about the availability of such services through intensive communication programs using all kinds of media (e.g., TV, radio, newspaper, billboard etc.). Through awareness, mHealth programs can create increased demand for this service [12]. Limited awareness is recognized as one of the obstacles that providers face in launching, scaling-up and sustaining mobile applications for health [42].

\section{Acceptability}

Simplest and proven technology driven applications have distinct advantages to scale [35]. In this case, cell phones are in an advantageous position to move forward mHealth paradigm because the infrastructure is already in place with a massive adoption of about 5 billion people in the world [41]. Furthermore, cell phone based simple applications (e.g., Frontline SMS or, mobile telemedicine platform) have widespread customer acceptance, because they provide easy, cost effective, useful solutions. Thus, this study believes that perceived ease of use and perceived usefulness of mHealth applications play a critical role to ensure broader reach and sustainable development.

\subsection{Service Quality}

Quality should be at the heart of all mHealth solutions to guarantee a high level of care for patients [36]. It is also seen as the right of patients to receive quality health care, whether it is delivered face-to-face or by means of modern ICT technologies [37]. Poor quality leads to complications and the need for additional care, which raises costs substantially [38]. There is growing concerns about the quality of such services due to lack of reliability and efficiency of the service delivery platform, knowledge and competence of the provider, privacy and security of information and above all, their effects on satisfaction, future use intentions and quality of health life [1]. In the followings, we have articulated different parameters of service quality in mHealth settings, which necessitate immediate attention. 


\section{A. Knowledge and Competence of the Provider}

Few healthcare professionals have the training, orientation, or time to adapt to hand-held devices with their complex inputs, difficult and unreliable applications, and fear of information loss [16]. In order to provide quality health services, they need to possess extra knowledge and skill on how to utilize mobile and wireless technologies safely and effectively [37]. Proper training will enable professionals to provide the best clinical judgment. The training would be a less complex issue as an increasing number of health care professionals can use hand-held and wireless devices; however, they need to be aware of the limitations of these systems [17]. Overall, it appears that setting qualifications and standards for mHealth professionals will be a major task [37].

\section{B. Capacity of Access \& Monitoring Devices}

mHealth service providers need to be aware of the shortcomings of mobile devices (e.g., cellular phones or, PDAs) in providing solutions to patients [12]. These devices have limitations in terms of screen size, processor power, memory, bandwidth and battery lives, which often restrict their capacity in application. For example, limited screen size and low image processing technology sometimes restrict the telemedicine applications, such as teleradiology, teledermatology and telepathology [37]. Furthermore, Health service providers should be aware of the underlying risk of a wrong or missed diagnosis, which might result from inadequate information or, technically corrupted image $[17,37]$.

In addition, efforts should be given to improve the capacity of monitoring devices for its measurement of vital signs. In addition, these devices should be able to store and transmit data to the central database for its right time application. In this case, the recent application of wireless body area networks (WBAN) creates a milestone in con- tinuous monitoring of multiple parameters in ambulatory settings [17, 37]. However, challenges remain to be overcome with regard to the development of such a setup in resource poor settings.

\section{Operational Compatibility}

Complexity in mHealth application often necessitates an integrated use of wireless platform, wired backbones and the Internet in a seamless manner [17, 37]. Thus, operational compatibility among multiple platforms represents a huge challenge for mHealth solutions. Furthermore, high speed communication networks are still not available in many resource poor settings. This absence might hinder the operations of some sophisticated mHealth applications (e.g., mobile telemedicine) which require converged high quality voice, video, and data.

\section{Information Interoperability}

Interoperability of information systems plays a crucial role in developing an integrated health information system for any country. However, this pursuit is often obstructed due to the noninteroperability of the different information systems, which ultimately limit access to information or exchange of data [17, 37]. For example, in Bangladesh, the patient database and electronic health records that mobile telemedicine platforms maintain on callers are not accessible by local clinics, laboratories or hospitals (and vice versa), thus, information sharing is not possible among the facilities to improve patient care [14]. Therefore, it is necessary to ensure common standards for the proper flow of data.

\subsection{Collaboration and Partnership}

mHealth field is now in a strong position to move forward by sharing techniques and applications with mobile operators, public health organizations and independent health service provid- ers [11]. Innovative partnerships are key to bringing promising mobile initiatives to scale [12]. The involvement of diverse stakeholder (e.g., patients, providers, corporate and regulators) paves the way for successful mHealth implementation. Upon such involvement, mHealth organizations can capture patient information at a single location and share those with other parties to ensure a complete picture. For instance, in Tanzania, an open source mobile data collection platform is linked with the computerized district health information system (DHIS) and also with clinical records databases; the database can then submit data to the DHIS to allow decentralized but comprehensive reporting of household and clinic-based data [12].

\subsection{An Enabling Policy and Operational Environment}

Healthcare regulations need to be conducive to encourage innovation in the marketplace, but restrictive enough to ensure service quality, protection of privacy and a high standard of care [14]. It is necessary to help regulators and educate policy makers through upto-date research and new developments in the field. According to Mechael [12], "The future of mHealth will depend on the establishment of a critical knowledge and evidence base that will enable health administrators and policy makers to make better informed decisions about how to invest limited health resources in technology".

\section{Conclusions}

Mobile communications are part of our everyday lives and for this reason alone, they have the potential to transform our wellness and healthcare [24, 25, 26]. Through our study, it is evident that health services using mobile platform will be the ultimate societal application. However, the overall development of 
this ubiquitous healthcare platform will be driven by the consumer demand, collaboration and time befitting regulations in the near future [37]. As such, an integrated approach is necessary to create an enabling environment for mHealth with user centric quality services, high-profile partnerships and media coverage [12]. It is widely expected that this ubiquitous healthcare will transform the healthcare system by serving the majority of unserved people in resource poor settings, providing a continuous quality of care in aging societies, and opening novel opportunities for global access to health services and medical knowledge [30, 31, 33, 34].

\section{References}

1. Akter S, D’Ambra J, Ray P. User perceived services quality of mHealth Services around the world. In the proceedings of the 18 th European Conference on Information Systems, Pretoria, South Africa, 2010.

2. Geissbuhler A. Access to health information: a key for better health in the knowledge society, Yearb Med Inform 2008;20-1.

3. Kuhn KA, Wurst SHR, Bott OJ, Giuse DA. Expanding the scope of health information systems: challenges and developments. Yearb Med Inform 2006.

4. Jen WY, Chao CC, Hung MC, Li YC, Chi YP. Mobile information and communication in the hospital outpatient service, Int J Med Inform 2007;76:565-74.

5. Anantharaman V, Swee HL. Hospital and emergency ambulance link: using IT to enhance emergency pre-hospital care. Int J Med Inform 2001;61 (2-3):147-61.

6. Krause A, Hartl D, Theis F, Stangl M, Gerauer KE, Mehlhorn AT, mobile decision support for transplantation patient data. Int J Med Inform 2004;73 (5):461-64.

7. Michalowski W, Rubin S, Slowinski R, Wilk S. Mobile clinical support system for pediatric emergencies: Decision Support Syst 2003;36:161-76.

8. Chau PYK, Hu PJH. Investigating healthcare professionals' decisions to accept telemedicine technology: an empirical test of competing theories. Inf Manage 2002;39(4):297-311

9. Andrade R, Wangenheim AV, Bortoluzzi MK. Wireless and PDA: a novel strategy to access DICOMcompliant medical data on mobile devices. Int $\mathrm{J}$ Med Inform 2003;71(23):157-63.

10. Zheng J.W, Zhang ZB, Wu TH, ZhangY. A wearable mobihealth care system supporting real-time diagnosis and alarm. Med Bio Eng Comput 2007; 45:877-85.

11. mHealth for Development: The opportunity of mobile technology for healthcare in developing world, http:// www.vitalwaveconsulting.com/ insights/mHealth.htm. Last Access May 12, 2010.

12. Mechael P. The Case for mHealth in Developing Countries. Mobilizing Markets: Special Edition of MIT Innovations Journal for the GSMA Mobile World Congress 2009, Cambridge: MIT Press; 2009. p. 153-68.

13. Istepanian R. Introduction to the Special Section on M-Health: Beyond Seamless Mobility and Global Wireless Health-care Connectivity. IEEE Trans Inf Technol Biomed 2004;8(4):405-13.

14. Ivatury G, Moore J, Bloch A. A doctor in your pocket: Health hotlines in developing countries, Mobilizing Markets: Special Edition of MIT Innovations. Journal for the GSMA Mobile World Congress 2009. Cambridge: MIT Press, 119-53.

15. Bardram JE, Baldus H, Favela J. Pervasive computing in hospitals. In: Bardram JE, Mihailidis A, Wan D. Boca Raton, FL, editors. Pervasive Computing in Healthcare. CRC Press; 2007. p. 49-77.

16. Varshney U. Pervasive Healthcare: Applications, Challenges and Wireless Solutions. Communications of the Association for Information Systems 2005;16(3): 57-72.

17. Varsheny U. Using wireless technologies in healthcare, International Journal of Mobile Communications 2006;4(3):354-68.

18. http://3gdoctor.wordpress.com/2010/03/22/the-definition-of-mhealth/ Last access May 10, 2010.

19. Kaplan WA. Can the ubiquitous power of mobile phones be used to improve health outcomes in developing countries? Global Health 2006;23(2):9.

20. Kalil T. Harnessing the mobile revolution. Mobilizing Markets: Special Edition of MIT Innovations Journal for the GSMA Mobile World Congress. Cambridge: MIT Press; 2009. p. 11-25

21. Blynn E. Piloting mHelath: a research scan; 2009. Available at: https:/wiki.brown.edu/confluence/download/attachments $/ 9994241 / \mathrm{mHealth}+$ Final.pdf? version=1. Last access May 12, 2010.

22. http://ww w.plusnews.org/Report. aspx?ReportId=80176. Last access May 12, 2010.

23. Li J, Moore N, Akter S, Bleistein S, Ray P. mHealth for Influenza Pandemic Surveillance in Developing Countries. In: Proceedings of the 43 Hawaii International Conference on System Sciences (HICSS), Hawaii, United States, January 5-8, 2010.

24. Norris T, Stockdale R, Sharma S. Mobile Health: Strategy and sustainability, J InfTechnol Healthcare 2008;6(5):326-33

25. Shields T, Chetley A, et al. ICT in the health sector: Summary of the online consultation. InfoDev Working paper 2010. www.infodev.org/en/ Document.84.aspx. Last access May 10, 2010

26. SatelLife. Handhelds for Health: SatelLife's Experiences in Africa and Asia. Watertown, MA: satelife; 2005.

27. http://www.unfoundation.org/global-issues/technology/disaster-relief-comms.html. Last access May 08, 2010.

28. http://www.msnbc.msn.com/id/35059343/ns/ world_news-haiti_earthquake/ Last access May 9, 2010

29. http://www.america.gov/st/develop-nglish/2010/February/201002041707471ejrehsiF0.8422663.html Last access May 12, 2010.

30. Breant C. Health information systems: current challenges and developments. Yearb Med Inform 2008

31. Demiris G, Hensel BK. Technology for an aging society: a systematic review of smart homes applications. Yearb Med Inform 2008

32. Facchetti A, Andrea R, Filippo MR,Alberto S. Mobile marketing: an analysis of key success factors and the European value chain, International Journal of Management and Decision Making 2005; $6(1): 65-80$ :

33. Le MoullecB, Ray P. Issues in E-Health Cost Impact Assessment. World Congress on Medical Physics and Biomedical Engineering, Munich, Germany, September 7 - 12, 2009.

34. Zuehlke P, Li J, Talai-Khoei A, Ray P. A Functional Specification for mobile eHealth (mHealth) Systems. The IEEE 11th International Conference on e-Health Networking, Application \& Services, Sydney Australia, December 16-18, 2009.

35. http://mobileactive.org/files/file_uploads/ mHealth $\% 20$ in $\% 20$ the $\% 20$ Global $\% 20$ South $\% 20$ \%20Landscape\%20Analysis.pdf). Last access May 12, 2010.

36. Ganapathy K; Ravindra A. mHealth: a potential tool for healthcare delivery in India, in the proceedings of making the eHealth connection, Bellagio, Italy, July 13-August 8, 2008.http://www.ehealthconnection.org/content/mhealth-and-mobiletelemedicine-an-overview Last access May 12, 2010.

37. Mishra S; Singh IP. mHealth: a developing country perspective, in the proceedings of making the eHealth connection, Bellagio, Italy, July 13-August 8, 2008. http://www.ehealth-connection.org/content/mhealthand-mobile-telemedicine-an-overview Last access May 12, 2010

38. Porter ME, Teisberg EO. Redefining healthcare: creating value based competition on results, Harvard business school press, Boston, Massachusetts, 2005.

39. Haux R. Healthcare and Informatics, On IMIA's opportunities and responsibilities in its 5th Decade. Yearb Med Inform 2008:1-6.

40. Lovis C. Sustainable health care systems: Yearb Med Inform 2007: 19-21

41.ht t p://ww w.grand challenges org/ MeasureHealthStatus/Topics/CellPhoneApps/ Pages/Round5.aspx Last access May 10, 2010.

42. http://www.itu.int/ITU-D/connect/ flagship_initiatives/mHealth.html Last access May 10,2010 .

\section{Correspondence to:}

Shahriar Akter and Pradeep Ray

Asia-Pacific ubiquitous Healthcare research Centre (APuHC)

Information Systems, Technology and Management

Australian School of Business (ASB)

University of New South Wales

Sydney, Australia 2052

E-mail: p.ray@unsw.edu.au 